\title{
Preferences for salt, sugar and fat in selected foods as determined by 6-n-propylthiouracil taster status in young adults
}

\author{
C. Gouillaud, T. Renault, E. Flipon, A. Dixon and S. Thondre \\ Functional Food Centre, Department of Sport and Health Sciences, Oxford Brookes University, Gipsy Lane, \\ Headington, Oxford OX3 OBP
}

Genetic differences in the ability to taste bitter compounds such as 6-n-propylthiouracil (PROP), classify human beings as supertasters, medium tasters and non-tasters ${ }^{(1)}$. Supertasters may tend to avoid bitter tasting vegetables whilst non-tasters have less ability to discriminate fat content in foods ${ }^{(2)}$. However, food choices of medium tasters are not often discussed. The aim of this study was to investigate PROP taster status in relation to preferences for salt, sugar and fat in selected, commonly consumed foods.

Fifty seven healthy volunteers ( $14 \mathrm{M} ; 43 \mathrm{~F})$ participated in the study. PROP taster status was determined by rating the taste intensity of five PROP solutions (concentrations $-3.2 \times 10^{-5}, 10 \cdot 0 \times 10^{-4}, 3 \cdot 2 \times 10^{-4}, 10.0 \times 10^{-3}$ and $3 \cdot 2 \times 10^{-3} \mathrm{~mol} / 1$ ) and five NaCl solutions (concentrations $-1,0 \cdot 5,0 \cdot 1,0 \cdot 05$ and $0.01 \mathrm{~mol} / \mathrm{l}$ ) on a 9-point category scale ${ }^{(3)}$. The participants also sampled butter (salted and unsalted), yogurt (full fat and fat free), tea (with and without sugar) and orange squash (with and without added sugar).

The baseline characteristics of the volunteers (supertasters $n=27$; medium tasters $n=30$ and non-tasters $n=0$ ) were not significantly different. Figure 1 shows that the medium tasters preferred salted butter more than the unsalted butter $(P=0 \cdot 005)$, full fat yogurt more than fat-free yogurt $(P=0.009)$ and tea with added sugar more than tea without sugar $(P=0 \cdot 005)$.

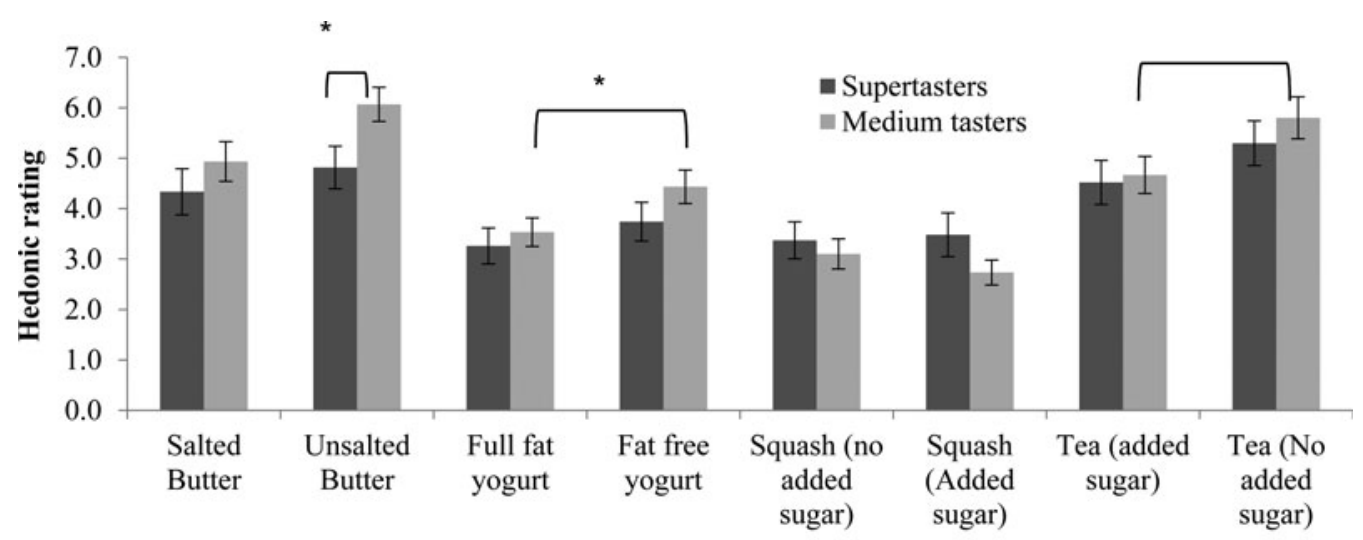

Food samples

Fig. 1. Hedonic ratings (Mean and SEM) from 1 (like extremely) to 9 (dislike extremely) for eight food stimuli with and without salt, fat and added sugar between medium tasters and supertasters. ( $* P<0.05$; Significant differences determined between groups by Independent T- test/Mann Whitney U- test and within groups by Paired T- test/Wilcoxon text)

The hedonic ratings for the foods tested were significantly different between supertasters and medium tasters, for unsalted butter alone $\left(P=0.04\right.$; Fig 1). This contradicts previous findings about supertasters' liking for salt ${ }^{(1)}$. To conclude, preferences for salt, sugar and fat were more evident in medium tasters than supertasters in this study, which failed to identify non-tasters. Such differences may potentially affect food choices, and therefore have an influence on an individual's nutritional intake and health status.

1. Hayes JE \& Keast RSJ (2011) Physiol Behav 104, 1072-1074.

2. Tepper B, Banni S, Melis M et al. (2014) Nutrients 6, 3363-3381.

3. Yackinous CA \& Guinard J (2002) Appetite 38, 201-209. 